\title{
Do Fixed Exchange Rates Cause Greater Integration?
}

\author{
Amr Sadek Hosny \\ University of Wisconsin-Milwaukee, Milwaukee, U. S. A.
}

\begin{abstract}
A classic argument in favor of a fixed exchange rate regime (ERR) has been the promotion of international trade between the pegging country and its base country. Results from previous literature point to a significant and highly positive effect of adopting a fixed ERR on bilateral trade between any given country pair. In this paper, it is argued that these results should not be interpreted as causal effects, since countries do not typically choose their ERR independently of their trade flows. This source of selection bias can be greatly reduced by using the matching approach in estimating treatment effects. Estimates of the effect of fixed ERR using this procedure are close to the ordinary least squares estimates reported in the literature, suggesting that there is little bias in these conventional estimates. These findings are robust to using different propensity score matching methods.
\end{abstract}

JEL Classifications: C21, F31, F41

Key words: Exchange Rate Regimes, International Trade, Causality, Matching Estimators, Treatment Effect, Gravity Equation

\footnotetext{
* Corresponding Author: Amr Sadek Hosny; Department of Economics, University of Wisconsin-Milwaukee, Northwest Quadrant Building B, Room 4428, Milwaukee, WI 53201, U. S. A.; Tel: +1 4142294375, Fax: +1 4142293860, E-mail: amrsadek@uwm.edu. 


\section{Introduction}

An enduring question in open-economy macroeconomics is whether to adopt a fixed or flexible exchange rate regime (ERR). A classic argument in favor of a more stable exchange rate has been the promotion of international trade between the pegging country and its base country. A number of papers, most using the gravity model have attempted to answer to this question. The gravity model basically models bilateral trade between any pair of countries as a function of their economic size, distance, and a number of variables that may promote or impede trade. A variable representing whether the country pair shares a fixed or flexible exchange rate regime is our variable of interest here, after controlling all other possible determinants of trade. Different papers have used different methodologies that have reached different, but quite comparable, estimates of the effect of a fixed ERR on bilateral trade between any given pair of countries. Table (1) lists some of these findings from the recent literature.

Table 1. Effects of Fixed Exchange Rates on Trade

\begin{tabular}{lccc}
\hline & Methodology & Coefficient & Effect \\
\cline { 2 - 4 } Klein and Shambaugh (2006) & OLS & $0.194^{* *}$ & $+21 \%$ \\
& Panel IV & $0.089)$ & \\
& & $0.495^{*}$ & $+64 \%$ \\
& Dynamic Panel & $0.10^{* * *}$ & $+11 \%$ \\
Adam and Cobham (2007) & (na) & \\
Bergin and Lin (2008) & OLS & $0.169^{* * *}$ & $+18 \%$ \\
Baranga (2010) & Panel & $(4.52)$ & \\
& & $0.23 * *$ & $+26 \%$ \\
& OLS & $(0.088)$ & \\
& & $0.154 * *$ & $+17 \%$ \\
& DD & $(0.0379)$ & \\
& & 0.0350 & $+4 \%$ \\
\hline
\end{tabular}

(Note) $* * * p<0.01, * * p<0.05, * p<0.1$

Standard errors are in parentheses

(Source) Adopted from Baranga (2010) 
Ordinary least squares estimates in Table 1 suggest that the effects of a fixed ERR on trade range from a $17 \%$ to $21 \%$ increase in trade. These estimates rely upon a rather strong assumption though; that is, that countries randomly choose their ERR independently of their existing trade relations.

A number of studies have then attempted different methodologies as a solution to this selection bias problem. Experimental methods are, of course, the prime candidates. However, these are not very easy to implement, especially in an international macroeconomic context. Baranga (2010) is one subtle exception. He exploits a natural experiment arising from the formation of the Euro to estimate the causal effect of fixed ERRs on trade. Baranga (2010) also performed a difference-in-difference (DD) exercise using the same dataset. The results from these methodologies return an insignificant effect of fixed ERRs on trade. A potential problem with this study is that it is limited to studying the effect of exchange rate regimes on trade between Euro members. Although Euro countries do comprise an increasingly large portion of world trade today, a significant amount of international trade still takes part outside of these sample countries. This study, however, covers 196 countries comprising almost 100\% of the world's trade, and covers the post-Bretton Woods period of 1973 2006.

Nichols (2007) discusses four methods to deal with the endogeneity problem. The first is panel models that typically require variables to be invariant over time. Examples of studies employing these methods are reported in Table 1. On the other hand, instrumental variable (IV) methods require the use of variables that affect the causal variable of interest (exchange rates) but not outcomes (trade). Estimates using these methods are typically higher than those of others. Klein and Shambaugh (2006) postulates a positive fixed exchange rate effect (64\%) on trade.

Regression Discontinuity (RD) methods have also been suggested in the treatment program evaluation literature. These require that treatment exhibit a discontinuous jump at a particular value of an observed assignment variable. This methodology, however, is not applicable to the context of this paper. Finally, an approach that has been proposed in the treatment literature is that of matching estimators. These estimators have been widely applied in the microeconomic program evaluation literature, and have only recently been applied to studying macroeconomic questions. This paper, as far as can be ascertained, is the first to employ matching methods to examine the causal effect of adopting a fixed ERR on bilateral trade between countries.

The rest of the paper is structured as follows. Section II describes the gravity model, and the data. Sections III and IV present the OLS and propensity score matching results, 
respectively. Finally, section V concludes.

\section{The Gravity Model}

Gravity models have become predominant in the last four decades in the empirical analysis of bilateral trade. They have been widely used to undertake the analysis of patterns and potential of trade and have proved to be very successful. Feenstra, Markusen, and Rose (2001, p.431) have argued that the gravity equation is one of the greatest success stories in empirical economics. The equation form has some similarity to the law of gravity in physics, which gave it the term, gravity model, as the Newtonian equation says that attraction (trade) depends on mass (economic size) and distance.

Specifically, an augmented version of the gravity model of international trade was estimated, following the specifications outlined by the seminal studies of Rose (2000; 2001), and adopted by Glick and Rose (2002) as represented by equations (1) to (3).

$$
\begin{aligned}
& \ln \left(T R A D E_{i j t}\right)=\beta_{0}+\beta_{1} \ln \left(D_{i s t_{i j t}}\right)+\beta_{2} \ln \left(G D P_{i} G D P_{j}\right)_{t}+\beta_{3} \ln \left(G D P P C_{i} G D P P C_{j}\right)_{t} \\
& +\beta_{4} \ln \left(\text { Area }_{i} \text { Area }_{j}\right)_{t}+\beta_{5} X_{i j}+\beta_{6} Z_{i j t}+\varepsilon_{i j t} \\
& X_{i j}=\beta_{5} \operatorname{ComLang}_{i j}+\beta_{6} \operatorname{ComBord}_{i j}+\beta_{7} \text { LandLock }_{i j}+\beta_{8} \text { Island }_{i j}+\beta_{9} \operatorname{ComCol}_{i j} \\
& +\beta_{10} \text { Colony }_{i j}+\beta_{11} \text { ComNat }_{i j} \\
& Z_{i j t}=\beta_{12} \operatorname{CurCol}_{i j t}+\beta_{13} C U_{i j t}+\beta_{14} F T A_{i j t}+\beta_{15} F x d_{i j t}
\end{aligned}
$$

where $i$ and $j$ represent every trading country pair, and $t$ denotes time. The technique basically regresses bilateral trade between pairs of countries on a number of timeinvariant $\left(X_{i j}\right)$ and time-variant $\left(Z_{i j t}\right)$ gravity model regressors, as well as a dummy variable $\left(F x d_{i j t}\right)$ indicating whether the countries have a fixed ERR or not. The latter variable is the variable of interest in this paper and is explained below.

Specifically, variables are defined as follows (also see Rose 2000; 2004): $\ln \left(T R A D E_{i j}\right)$ is the value of bilateral trade between countries $i$ and $j$ at time $t$. The data comes from the IMF Direction of Trade Statistics (DOTS). $\ln \left(D_{i s t} t_{i j}\right)$ is the distance between countries $i$ and $j \cdot \ln \left(G D P_{i} G D P_{j}\right)_{t}$ is the product of the real GDP of countries $i$ and $j \cdot \ln \left(G D P P C_{i} G D P P C_{j}\right)_{t}$ is the product of the real GDP per capita of countries $i$ 
and $j . \ln \left(\text { Area }_{i} \text { Area }_{j}\right)_{t}$ is the product of the areas of countries $i$ and $j$, measured in square kilometers. ComLang ij $_{\text {ij }}$ a dummy (binary) variable equal to 1 if countries $i$ and $j$ have a common language. ComBord $_{i j}$ is a dummy variable equal to 1 if countries $i$ and $j$ share a common border. LandLock ${ }_{i j}$ is the number of landlocked countries among countries $i$ and $j$. Island ${ }_{i j}$ is the number of island countries among countries $i$ and $j$. ComCol $i j$ is a dummy variable equal to 1 if countries $i$ and $j$ have ever been colonies of the same colonizer. Colony $y_{i j}$ is a dummy variable equal to 1 if country $i$ ever colonized country $j$. $\mathrm{ComNat}_{i j}$ is a dummy variable equal to 1 if countries $i$ and $j$ are part of the same nation. $\mathrm{CurCol}_{i j t}$ is a dummy variable equal to 1 if country $i$ is a colony of $j$ at time $t$ or vice versa. $C U_{i j t}$ is a dummy variable equal to 1 if countries $i$ and $j$ share the same currency at time $t$. FTA $A_{i j t}$ is a dummy variable equal to 1 if countries $i$ and $j$ are members of the same Free Trade Agreement at time $t$. Fxd $d_{i j t}$ is a dummy variable equal to 1 if countries $i$ and $j$ share a fixed ERR at time $t$.

Annual data on the dependent variable, bilateral trade and the independent variables, and all other regressors, except $\left(F x d_{i j t}\right)$, come from Rose (2004) and Rose and Spiegel (2011) and cover the post-Bretton Woods period of 1973 1999.

To construct the $\left(F x d_{i j t}\right)$ dummy variable, information from Rose and Spiegel (2011) was used and the exchange rate classification system developed by Shambaugh (2004) and used by Klein and Shambaugh (2006) was built on. What makes this classification system appealing is that it is based on the actual behavior of countries' exchange rates, and thus is a de facto classification system. More specifically, a particular country is considered to have a fixed exchange rate with its base country in any given year if its bilateral exchange rate stays within a $\pm 2 \%$ band. Base countries include major countries such as the United States, France, the United Kingdom, and Germany, as well as those that are important within a given region, such as India, Australia, and South Africa. ${ }^{1}$ Table 2 presents descriptive statistics on both fixed and non-fixed observations.

${ }^{1}$ For a detailed description of this classification methodology, see Shambaugh (2004). 
Table 2. Descriptive Statistics

\begin{tabular}{cccccc|ccccc}
\hline & \multicolumn{5}{c|}{ Non-Fixed exchange rate } & \multicolumn{5}{c}{ Fixed exchange rate } \\
\cline { 2 - 12 } & Obs & Mean & Std. Dev. & Min & Max & Obs & Mean & Std. Dev. & Min & Max \\
\cline { 2 - 12 } Ln(trade) & 396,141 & 16.508 & 2.942 & -15.135 & 27.011 & 2,049 & 18.213 & 2.384 & 8.359 & 23.392 \\
Ln(dist) & 565,892 & 8.143 & 0.825 & 3.684 & 9.421 & 2,322 & 7.873 & 0.764 & 5.303 & 9.258 \\
Ln(GDP) & 459,434 & 35.410 & 2.678 & 23.512 & 46.001 & 1,959 & 35.542 & 2.814 & 23.238 & 41.346 \\
Ln(GDPPC) & 459,434 & 17.331 & 1.570 & 11.789 & 22.190 & 1,959 & 18.126 & 1.431 & 13.443 & 21.903 \\
Ln(Area) & 565,907 & 23.549 & 3.602 & 4.916 & 33.034 & 2,322 & 23.160 & 3.729 & 9.367 & 28.346 \\
ComLang & 565,907 & 0.191 & 0.393 & 0 & 1 & 2,322 & 0.779 & 0.414 & 0 & 1 \\
ComBord & 565,907 & 0.026 & 0.162 & 0 & 1 & 2,322 & 0 & 0 & 0 & 0 \\
LandLock & 565,907 & 0.276 & 0.492 & 0 & 2 & 2,322 & 0.144 & 0.351 & 0 & 1 \\
Island & 565,907 & 0.355 & 0.549 & 0 & 2 & 2,322 & 0.524 & 0.621 & 0 & 2 \\
ComCol & 565,907 & 0.092 & 0.289 & 0 & 1 & 2,322 & 0.108 & 0.311 & 0 & 1 \\
Colony & 565,907 & 0.014 & 0.121 & 0 & 1 & 2,322 & 0.444 & 0.451 & 0 & 1 \\
ComNat & 565,907 & 0.001 & 0.034 & 0 & 1 & 2,322 & 0.054 & 0.226 & 0 & 1 \\
CurCol & 565,907 & 0.001 & 0.038 & 0 & 1 & 2,322 & 0.062 & 0.242 & 0 & 1 \\
CU & 565,907 & 0.012 & 0.109 & 0 & 1 & 2,322 & 0 & 0 & 0 & 0 \\
FTA & 565,907 & 0.221 & 0.415 & 0 & 1 & 2,322 & 0.124 & 0.329 & 0 & 1 \\
\hline
\end{tabular}

\section{Regression Results}

This section uses the gravity model to estimate the role of a fixed ERR on bilateral trade between any given pair of countries. Table 3 presents the OLS core results that will serve as a benchmark throughout the remainder of this paper. Most regressors show the expected signs. We can see a statistically significant relationship between the bilateral trade of any given country pair and whether they share a fixed ERR. When adding year effects (column 2), the coefficient on fixed ERR is reduced in magnitude, but is still statistically significant at the $99 \%$ confidence level. 


\section{Table 3. OLS Benchmark Results}

\begin{tabular}{|c|c|c|}
\hline & $\begin{array}{c}\text { Full Sample: } \\
\text { Dep. Var.: TRADE }\end{array}$ & $\begin{array}{c}\text { Full Sample: } \\
\text { Dep. Var.: TRADE }\end{array}$ \\
\hline \multicolumn{3}{|l|}{ Independent variables } \\
\hline \multirow[t]{2}{*}{ Distance } & -1.054 & -1.038 \\
\hline & $(68.64) * * *$ & $(68.60)^{* * *}$ \\
\hline \multirow[t]{2}{*}{$\left(G D P_{i} G D P_{j}\right)$} & 0.902 & 0.912 \\
\hline & $(120.93)^{* * *}$ & $(123.35)^{* * *}$ \\
\hline \multirow[t]{2}{*}{$\left(G D P P C_{i} G D P P C_{j}\right)$} & 0.361 & 0.369 \\
\hline & $(36.33) * * *$ & $(37.51)^{* * *}$ \\
\hline \multirow[t]{2}{*}{$\left(\right.$ Area $_{i}$ Area $\left._{j}\right)$} & -0.044 & -0.055 \\
\hline & $(7.69)^{* * *}$ & $(9.68)^{* * *}$ \\
\hline \multirow[t]{2}{*}{ Com Language } & 0.524 & 0.489 \\
\hline & $(17.10)^{* * *}$ & $(16.14)^{* * *}$ \\
\hline \multirow[t]{2}{*}{ Com Border } & 0.798 & 0.777 \\
\hline & $(11.15)^{* * *}$ & $(10.81)^{* * *}$ \\
\hline \multirow[t]{2}{*}{ Land Locked } & -0.512 & -0.441 \\
\hline & $(23.89) * * *$ & $(21.09) * * *$ \\
\hline \multirow[t]{2}{*}{ Island } & 0.171 & 0.150 \\
\hline & $(6.15)^{* * *}$ & $(5.49)^{* * *}$ \\
\hline \multirow[t]{2}{*}{ Com Colonizer } & 0.541 & 0.558 \\
\hline & $(10.98)^{* * *}$ & $(11.42)^{* * *}$ \\
\hline \multirow[t]{2}{*}{ Colony } & 1.243 & 1.195 \\
\hline & $(15.98)^{* * *}$ & $(15.21)^{* * *}$ \\
\hline \multirow[t]{2}{*}{ Com Nation } & 0.033 & 0.138 \\
\hline & $(0.06)$ & $(0.26)$ \\
\hline \multirow[t]{2}{*}{ Cur Colony } & 0.535 & 0.299 \\
\hline & $(2.44)^{* *}$ & (1.33) \\
\hline \multirow[t]{2}{*}{$C U$} & 0.878 & 0.914 \\
\hline & $(9.88)^{* * *}$ & $(10.58)^{* * *}$ \\
\hline \multirow[t]{2}{*}{ FTA } & 0.032 & 0.132 \\
\hline & $(1.46)$ & $(5.87) * * *$ \\
\hline \multirow[t]{2}{*}{$F x d$} & 0.409 & 0.397 \\
\hline & $(4.31)^{* * *}$ & $(4.07)^{* * *}$ \\
\hline Year Effects & $\mathrm{N}$ & $\mathrm{Y}$ \\
\hline Observations & 331,442 & 331,442 \\
\hline R-squared & 0.678 & 0.687 \\
\hline
\end{tabular}

(Note) $* * * p<0.01, * * p<0.05, * p<0.1$

OLS results with intercept and year effects (column 2 ) not reported.

Robust standard errors (clustering by country pairs) are in parentheses 
Table 4. Sensitivity Analysis

\begin{tabular}{|c|c|c|c|c|c|c|c|}
\hline & \multicolumn{7}{|c|}{ Panel A: Cross Sectional Results } \\
\hline & $(1975)$ & $(1980)$ & (1985) & (1990) & (1995) & $(2000)$ & $(2005)$ \\
\hline Fxd & $\begin{array}{c}0.752 \\
(0.225)^{* * *}\end{array}$ & $\begin{array}{c}0.291 \\
(0.186)\end{array}$ & $\begin{array}{c}0.432 \\
(0.155)^{* * *}\end{array}$ & $\begin{array}{c}0.349 \\
(0.136)^{* *}\end{array}$ & $\begin{array}{c}0.329 \\
(0.109)^{* * *}\end{array}$ & $\begin{array}{c}0.325 \\
(0.091)^{* * *}\end{array}$ & $\begin{array}{c}0.616 \\
(0.191)^{* * *}\end{array}$ \\
\hline Obs & 5,768 & 6,614 & 7,502 & 9,199 & 12,906 & 15,862 & 4,425 \\
\hline \multirow[t]{3}{*}{ R-squared } & 0.642 & 0.656 & 0.659 & 0.673 & 0.671 & 0.708 & 0.827 \\
\hline & \multicolumn{7}{|c|}{ Panel B: Different Country Types } \\
\hline & & $\begin{array}{l}\text { Developing/ } \\
\text { Developing }\end{array}$ & $\begin{array}{l}\text { Developing/ } \\
\text { Developing }\end{array}$ & $\begin{array}{l}\text { Industrial/ } \\
\text { Developing }\end{array}$ & $\begin{array}{l}\text { Industrial/ } \\
\text { Developing }\end{array}$ & & \\
\hline Fxd & & $\begin{array}{l}-0.311 \\
(0.252)\end{array}$ & $\begin{array}{l}-0.486 \\
(0.250)\end{array}$ & $\begin{array}{c}0.449 \\
(0.089) * * *\end{array}$ & $\begin{array}{c}0.464 \\
(0.090)^{* * *}\end{array}$ & & \\
\hline Year Effects & & $\mathrm{N}$ & $\mathrm{Y}$ & $\mathrm{N}$ & $\mathrm{Y}$ & & \\
\hline Obs & & 152,726 & 152,726 & 178,716 & 178,716 & & \\
\hline \multirow[t]{3}{*}{ R-squared } & & 0.532 & 0.541 & 0.763 & 0.770 & & \\
\hline & \multicolumn{7}{|c|}{ Panel C: Different Regions } \\
\hline & & & (MENA) & (Sub Saharn) & (East Asia) & & \\
\hline Fxd & & & $\begin{array}{c}0.091 \\
(0.079)\end{array}$ & $\begin{array}{c}0.184 \\
(0.158)\end{array}$ & $\begin{array}{c}0.623 \\
(0.209)^{* * * *}\end{array}$ & & \\
\hline Year Effects & & & Y & Y & Y & & \\
\hline Obs & & & 36,098 & 98,290 & 49,969 & & \\
\hline \multirow[t]{3}{*}{ R-squared } & & & 0.611 & 0.528 & 0.675 & & \\
\hline & \multicolumn{7}{|c|}{ Panel D: Different Income Groups } \\
\hline & & $\begin{array}{l}\text { Lower } \\
\text { income }\end{array}$ & $\begin{array}{l}\text { Lower-middle } \\
\text { income }\end{array}$ & $\begin{array}{l}\text { Upper-middle } \\
\text { income }\end{array}$ & $\begin{array}{c}\text { High } \\
\text { income }\end{array}$ & & \\
\hline Fxd & & $\begin{array}{c}0.428 \\
(0.176)^{* *}\end{array}$ & $\begin{array}{c}0.675 \\
(0.171)^{* * *}\end{array}$ & $\begin{array}{c}0.424 \\
(0.157)^{* * *}\end{array}$ & $\begin{array}{c}0.308 \\
(0.088) * * *\end{array}$ & & \\
\hline Year Effects & & Y & $\mathrm{Y}$ & Y & $\mathrm{Y}$ & & \\
\hline Obs & & 45,878 & 102,896 & 170,969 & 209,277 & & \\
\hline R-squared & & 0.490 & 0.545 & 0.625 & 0.736 & & \\
\hline
\end{tabular}

(Note) $* * * p<0.01, * * p<0.05, * p<0.1$

OLS results with intercept and year effects not reported.

Robust standard errors (clustering by country pairs) are in parentheses.

All other regressors in Table 3 are estimated but not reported. 
Table 4 presents a number of sensitivity analyses. In Panel A, the gravity equation on a cross section at the beginning of every five year period is estimated. The results indicate that a fixed ERR has almost always been important and do not seem to show any specific effect over the different years reported.

Panel B estimates the equation using different country types. The coefficient on fixed ERR is significant only when we consider trade between industrial and developing countries. If we limit the sample to trade between developing countries, then the coefficient of interest is no longer significant. This finding suggests that trade mostly follows the lines of inter-industry trade. Specifically, the Linder hypothesis, according to Linder (1961), states that intra-industry trade should increase between similar countries. On the other hand, comparative advantage theory states that inter-industry should increase between dissimilar countries. ${ }^{2}$

Panel C reports results for different geographic regions. Finally, Panel D reports results for different income groups. Income group classifications are adopted from the World Bank website. ${ }^{3}$ Results indicate that a fixed ERR is almost equally important in all different income groups.

\section{Causality}

Results from the previous section should not be interpreted as causal effects, since an underlying assumption here is that countries choose their ERR independently of their trade flows. But countries typically do not randomly enter into a fixed ERR, but rather choose to peg against the currency of one of their major trading partners. This source of selection bias is greatly reduced when using the matching approach to estimate treatment effects using non-experimental observational data. Results from the above OLS regression, however, may still serve as a benchmark against which the results from the treatment estimators can be compared.

Specifically, the Average Treatment Effect (ATE) and the Average Treatment Effect on the Treated (ATT) are defined as follows:

\footnotetext{
${ }^{2}$ Intra-industry trade differs from inter-industry trade. Intra-industry trade refers to trade between two countries of products belonging to the same industry, while inter-industry trade refers to trade between two countries of products of different industries.

${ }^{3}$ Specifically, economies are divided according to 2011 GNI per capita, calculated using the World Bank Atlas method. The groups are: low income (LIC), \$1,025 or less; lower middle income (LMIC), \$1,026 - \$4,035; upper middle income (UMIC), \$4,036 - \$12,475; and high income (HIC), $\$ 12,476$ or more.
} 


$$
\begin{gathered}
A T E=E\left[Y_{1 i j t}-Y_{0 i j t}\right] \\
A T T=E\left[Y_{1 i j t}-Y_{0 i j t} \mid T_{i j t}=1\right]
\end{gathered}
$$

where $Y_{1 i j t}$ and $Y_{0 i j t}$ are the potential outcomes in the case of treatment (fixed ERR, $T_{i j t}$ $=1$ ), and no treatment (not fixed ERR, $T_{i j t}=0$ ) for countries $i$ and $j$ at time $t$. Of course, only one of these two potential outcomes can be observed at any point in time. This problem has been labeled the fundamental problem of causal inference (Holland 1986). In practice, one only observes the variable $Y_{i j t}$, which we can relate to the measures of potential outcomes as follows:

$$
Y_{i j t}= \begin{cases}Y_{1 i j t} & \text { if } T_{i j t}=1 \\ Y_{0 i j t} & \text { if } \quad T_{i j t}=0\end{cases}
$$

In this context, the ATE asks the question: What would the bilateral trade value have been in this sample had countries been randomly treated (adopted a fixed ERR)? On the other hand, the ATT asks the following question: What would the bilateral trade value of fixed ERR countries have been in this sample had they decided to have a fixed ERR?

A necessary assumption in this context is the following:

$$
Y_{1 i j t,} Y_{0 i j t} \mid T_{i j t} \perp X_{i j t}
$$

where $\perp$ denotes independence. Different versions of this assumption have been identified in the literature. It has been referred to as the unconfoundedness assumption (Rosenbaum and Rubin 1983), selection on observables (Heckman and Robb 1985), or the conditional independence assumption (Lechner 1999). Simply, it means that conditional on the observed pre-treatment characteristics of countries $i$ and $j$, a vector of variables $X_{i j t}$, the assignment of the treatment is independent of potential outcomes. This assumption guarantees the identification of the ATE and ATT.

Another requirement is the common support condition:

$$
0<P\left(T_{i j t}=1 \mid X_{i j t}\right)<1
$$

This condition rules out the perfect predictability of $T_{i j t}$ given the covariates $X_{i j t}$. It simply states that units with the same pretreatment observable characteristics will have 
a positive probability of being both treated and control units.

Instead of conditioning on $X_{i j t}$, it is possible to condition on the propensity score. Rosenbaum and Rubin (1983) defined propensity scores, $p(X)$, as the conditional probability of receiving the treatment given the covariates. They further showed that if potential outcomes are independent of the treatment assignment conditional on covariates $X_{i j t}$, then they are also independent of the treatment conditional on the propensity score, $p(X)$.

$$
p(X)=\operatorname{Pr}\left(T_{i j t}=1 \mid X_{i j t}\right)=E\left(T_{i j t} \mid X_{i j t}\right)
$$

The unconfoundedness assumption can now be written as:

$$
Y_{1 i j t}, Y_{0 i j t} \mid T_{i j t} \perp p(X)
$$

Under these assumptions, ATE and ATT can be re-written as follows:

$$
\begin{gathered}
A T E_{P S M}=E\left[Y_{1 j i t}-Y_{0 i j t} \mid p(X)\right]=E\left[Y_{1 i j t} \mid T_{i j t}=1, p(X)\right]-E\left[Y_{0 i j t} \mid T_{i j t}=0, p(X)\right] \\
A T T_{P S M}=E\left[Y_{1 i j t}-Y_{0 i j t} \mid T_{i j t}=1, p(X)\right] \\
=E\left[E\left[Y_{1 i j t} \mid T_{i j t}=1, p(X)\right]-E\left[Y_{0 i j t} \mid T_{i j t}=0, p(X)\right] T_{i j t}=1\right]
\end{gathered}
$$

Simply, computing the ATT using the PSM estimator boils down to calculating the mean difference in outcomes of the treated and control units, appropriately weighted by the propensity score distribution of the participants.

\section{Propensity Score Matching}

In this section, propensity score matching estimators to compare between treated (fixed ERR) and control (flexible ERR) countries are used, the average treatment effect on the outcome is measured. Propensity-score matching essentially estimates each country's propensity to receive a binary treatment (with a probit or logit) as a function of observables and matches countries with similar propensities. When countries have similar propensity scores, their assignment to the treated group is largely random with respect to the relevant covariates, and thus mimics a controlled experiment, making it possible to accurately identify causal effects.

Different propensity score matching estimators have been proposed in the literature. 
Morgan and Harding (2006) and Caliendo and Kopeinig (2008) provide extensive discussions of practical and theoretical issues in propensity score estimation and comparisons of different types of matching estimators used to estimate the treatment effects. For applications, see Becker and Ichino (2002), Abadie et al. (2004), and Nichols (2007).

The first step is to estimate the propensity score. Table 5 reports the results of estimating the propensity score using logit and probit, with and without year effects. In what follows, the propensity score is estimated using logit, with and without year effects.

Table 5. Propensity Score Estimation

\begin{tabular}{|c|c|c|c|c|}
\hline & $\begin{array}{c}\text { Logit: } \\
\text { Dep. Var.: Fxd }\end{array}$ & $\begin{array}{c}\text { Logit: } \\
\text { Dep. Var.: } F x d\end{array}$ & $\begin{array}{c}\text { Probit: } \\
\text { Dep. Var.: Fxd }\end{array}$ & $\begin{array}{c}\text { Probit: } \\
\text { Dep. Var.: } F x d\end{array}$ \\
\hline \multicolumn{5}{|l|}{ Independent variables } \\
\hline \multirow[t]{2}{*}{ Distance } & -1.131 & -1.127 & -0.415 & -0.412 \\
\hline & $(34.73) * * *$ & $(34.13) * * *$ & $(30.51)^{* * *}$ & $(29.98) * * *$ \\
\hline \multirow[t]{2}{*}{$\left(G D P_{i} G D P_{j}\right)$} & -0.243 & -0.238 & -0.099 & -0.096 \\
\hline & $(15.42)^{* * *}$ & $(14.73)^{* * *}$ & $(15.35)^{* * *}$ & $(14.47)^{* * *}$ \\
\hline \multirow[t]{2}{*}{$\left(G D P P C_{i} G D P P C_{j}\right)$} & 0.578 & 0.582 & 0.263 & 0.266 \\
\hline & $(23.78) * * *$ & $(23.81) * * *$ & $(25.79) * * *$ & $(25.90) * * *$ \\
\hline \multirow[t]{2}{*}{$\left(\right.$ Area $_{i}$ Area $\left._{j}\right)$} & 0.245 & 0.242 & 0.088 & 0.086 \\
\hline & $(21.66)^{* * *}$ & $(20.90) * * *$ & $(18.68)^{* * *}$ & $(17.94)^{* * *}$ \\
\hline \multirow[t]{2}{*}{ Com Language } & 2.295 & 2.291 & 0.801 & 0.799 \\
\hline & $(36.68) * * *$ & $(36.53) * * *$ & $(35.79) * * *$ & $(35.63) * * *$ \\
\hline \multirow[t]{2}{*}{ Land Locked } & 0.047 & 0.063 & -0.106 & -0.094 \\
\hline & $(0.74)$ & $(0.98)$ & $(3.89)^{* * *}$ & $(3.42)^{* * *}$ \\
\hline \multirow[t]{2}{*}{ Island } & 0.582 & 0.583 & 0.190 & 0.190 \\
\hline & $(11.34)^{* * *}$ & $(11.35)^{* * *}$ & $(9.01)^{* * *}$ & $(8.99)^{* * *}$ \\
\hline \multirow[t]{2}{*}{ Com Colonizer } & -0.736 & -0.739 & -0.263 & -0.266 \\
\hline & $(7.15)^{* * *}$ & $(7.16)^{* * *}$ & $(6.57)^{* * *}$ & $(6.60) * * *$ \\
\hline \multirow[t]{2}{*}{ Colony } & 3.194 & 3.186 & 1.377 & 1.372 \\
\hline & $(52.20) * * *$ & $(51.89) * * *$ & $(50.63)^{* * *}$ & $(50.29) * * *$ \\
\hline \multirow[t]{2}{*}{ Cur Colony } & 0.068 & 0.025 & -0.152 & -0.186 \\
\hline & $(0.23)$ & $(0.08)$ & $(1.03)$ & $(1.24)$ \\
\hline \multirow[t]{2}{*}{ FTA } & -1.741 & -1.718 & -0.682 & -0.665 \\
\hline & $(18.64)^{* * *}$ & $(18.02)^{* * *}$ & $(18.94)^{* * *}$ & $(18.07)^{* * *}$ \\
\hline Year Effects & $\mathrm{N}$ & $\mathrm{Y}$ & $\mathrm{N}$ & $\mathrm{Y}$ \\
\hline Observations & 396,141 & 396,141 & 396,141 & 396,141 \\
\hline
\end{tabular}

(Note) $* * * p<0.01, * * p<0.05, * p<0.1$

intercept (columns 1,2,3,4) and year effects (columns 2,4) not reported.

Standard errors are in parentheses 
The second step is to choose a matching algorithm. The three most widely used matching estimators are Nearest-Neighbor Matching, Kernel Matching, and Stratification Matching. Heckman, Ichimura, and Todd (1997, 1998) and Smith and Todd (2005) provide a general outline for understanding different matching estimators. Using their framework, all three matching estimators of the ATT can be represented as follows:

$$
A T T=\frac{1}{n^{1}} \sum_{1}\left\{\left(y_{1 i j t} \mid T_{i j t}=1\right)-\sum_{j} \omega_{1,0}\left(y_{0 i j t} \mid T_{i j t}=0\right)\right\}
$$

where $n^{l}$ is the number of treatment cases and $\omega_{i j}$ represents a set of scaled weights that measure the distance between each control unit and the target treatment unit. According to a survey of Morgan and Harding (2006), these estimators differ primarily in (a) the number of matches designated for each to-be-matched target case and (b) how these multiple matches are weighted, $\omega_{1,0}$, if more than one is used.

Beginning with the Stratification estimator (sometimes referred to as interval matching), this method sorts the range of variation of the propensity score into a set of intervals (strata) such that within each interval, treated and control units have, on average, the same propensity score (Rosenbaum and Rubin, 1983; Cochran, 1968). For each interval, the difference between the average outcomes of the treated and the controls is computed and the ATT is obtained as the mean of the ATT of each of these intervals, weighted by the number of treated units in each interval.

A potential problem with the Stratification method is that it may discard observations in intervals in which treated units are discarded because no control is available in their specific interval. This problem can be overcome by using the Nearest Neighbor (NN) matching method. This method searches for control units with the nearest propensity score to those of each treated unit (Rubin 1973a; 1973b; Rosenbaum and Rubin, 1983). These matched control units are used to construct the counterfactual for the treated units. Since a control unit can be a best match for more than one treated unit, this method can be applied with or without replacement. With replacement, every matched control unit will be returned to the pool after the match and can subsequently be used as a match again. However, without replacement, every matched control unit is considered only once. Caliendo and Kopeinig (2008), however, argue that matching with replacement involves a trade-off between efficiency and bias. The difference between the outcomes of the treated and the matched control units is computed, and the ATT is then obtained by averaging these differences. 
Another problem that could arise in this context is that some matches may be fairly poor. It is possible that some treated units may have a nearest neighbor that is not so near, i.e.; may have a very different propensity score. This is why the Kernel Matching method has been introduced. In Kernel Matching, the counterfactual for each treatment case is constructed using all possible control units, but each control unit is weighted based on its distance from the treated unit. Specifically, these weights, represented by $\omega_{1,0}$, are calculated using a kernel function that transforms the distance between the selected target treatment unit and all control units in the study (Heckman, Ichimura, and Todd 1997, 1998, Smith and Todd 2005). The non-parametric Kernel Matching estimator is thus a natural extension of Stratification and Nearest Neighbor matching methods, since it simply matches all control units to each treatment unit but weights it so that those closest to the treatment unit are given the greatest weight.

Table 6 presents the estimated results using the different estimators. Estimated results using the NN matching are in Panel A, while Panel B presents those from the Kernel and Stratification Matching estimators.

The number of treated and control units are shown for both on and off the common support condition. As mentioned above, the common support condition excludes the control units that are beyond the calculated minima and maxima of the propensity score - the probability distributions of the variables in $X_{i j t}$ - among the treated units. All estimated results in Table 6 are estimated after imposing the common support condition. 
Table 6. Propensity Score Matching: ATT

\begin{tabular}{|c|c|c|c|c|c|c|}
\hline & & Panel & Nearest $N$ & hbor (NN) $N$ & tching & \\
\hline & NN(norepl) & NN(norepl) & NN(repl) & NN(repl) & NN(bias) & NN(bias) \\
\hline$F x d$ & $\begin{array}{l}.417 * * * \\
(.062)\end{array}$ & $\begin{array}{c}.346 * * * \\
(.064)\end{array}$ & $\begin{array}{l}.424 * * \\
(.102)\end{array}$ & $\begin{array}{l}.291^{*} \\
(.095)\end{array}$ & $\begin{array}{c}.502 * * * \\
(.093)\end{array}$ & $\begin{array}{l}.275^{* * *} \\
(.045)\end{array}$ \\
\hline $\begin{array}{c}\text { Year Effects } \\
\text { \#Treated Units }\end{array}$ & $\mathrm{N}$ & $\mathrm{Y}$ & $\mathrm{N}$ & $\mathrm{Y}$ & $\mathrm{N}$ & $\mathrm{Y}$ \\
\hline $\begin{array}{c}\text { Off support } \\
\text { [On support] }\end{array}$ & $\begin{array}{c}135 \\
{[1,648]}\end{array}$ & $\begin{array}{c}149 \\
{[1,634]}\end{array}$ & $\begin{array}{c}135 \\
{[1,648]}\end{array}$ & $\begin{array}{c}149 \\
{[1,634]}\end{array}$ & $\begin{array}{c}1,783 \\
169,387\end{array}$ & $\begin{array}{c}1,783 \\
169,387\end{array}$ \\
\hline $\begin{array}{c}\text { \#Control Units } \\
\text { Off support } \\
\text { [On support] }\end{array}$ & $\begin{array}{l}167,739 \\
{[1,648]}\end{array}$ & $\begin{array}{l}167,753 \\
{[1,634]}\end{array}$ & $\begin{array}{c}6,933 \\
{[162,454]}\end{array}$ & $\begin{array}{c}10,649 \\
{[158,738]}\end{array}$ & & \\
\hline & & Panel B & Kernel and & ratification & atching & \\
\hline & & Kernel & Kernel & Strata & Strata & \\
\hline Fxd & & $\begin{array}{l}.434 * * * \\
(.066)\end{array}$ & $\begin{array}{l}.341 * * * \\
(.063)\end{array}$ & $\begin{array}{c}0.332 * * * \\
(0.076)\end{array}$ & $\begin{array}{c}0.377 * * * \\
(0.081)\end{array}$ & \\
\hline $\begin{array}{l}\text { Year Effects } \\
\text { \#Treated Units }\end{array}$ & & $\mathrm{N}$ & Y & $\mathrm{N}$ & Y & \\
\hline $\begin{array}{l}\text { Off support } \\
\text { [On support] }\end{array}$ & & $\begin{array}{c}148 \\
{[1,635]}\end{array}$ & $\begin{array}{c}151 \\
{[1,632]}\end{array}$ & $\begin{array}{c}103 \\
{[1,680]}\end{array}$ & $\begin{array}{c}149 \\
{[1,634]}\end{array}$ & \\
\hline \#Control Units & & & & & & \\
\hline $\begin{array}{l}\text { Off support } \\
\text { [On support] }\end{array}$ & & $\begin{array}{c}62,684 \\
{[106,703]}\end{array}$ & $\begin{array}{c}67,026 \\
{[102,361]}\end{array}$ & $\begin{array}{c}6,830 \\
{[162,557]}\end{array}$ & $\begin{array}{c}10,500 \\
{[158,887]}\end{array}$ & \\
\hline
\end{tabular}

(Note) $* * * p<0.01, * * p<0.05, * p<0.1$

Standard errors are in parentheses. Bootstrap standard errors for the Stratification estimator.

Off support [on support] in treated and control observations. (no)repl: (no)replacement, bias: bias-corrected nearest neighbor matching estimator.

In Panel A, the first two columns present empirical estimated results with no replacement; that is, once a control unit is matched against a treated unit, it cannot be matched to another one. Columns 3 and 4 present estimated results with replacement, while columns 5 and 6 present the bias-corrected nearest neighbor matching estimator. Abadie and Imbens (2002) showed that the simple matching estimator is biased in finite samples when the matching is not exact. Specifically, they show that, with $k$ continuous covariates, the simple estimator will have a bias term corresponding to the differences in covariates between the matched and control units. The bias-corrected matching estimator adjusts the difference within the matches for the differences in their covariate values (Abadie et al. 2004). All estimated coefficients in these different classes of the $\mathrm{NN}$ estimator are very close to the range reported when using the OLS estimator in the 
previous section. Finally, estimated results using Kernel Matching and Stratification Matching estimators reported in Panel B also show that the fixed ERR coefficient is within the same range as reported in previous literature. Using these estimated coefficients, one can conclude that the (causal) effect of adopting a fixed ERR on bilateral trade is in the approximate order of 25-50 percent.

These results provide strong support for the positive significant effects of a fixed ERR on bilateral trade between any given pair of countries. These findings improve on the OLS results reported in earlier literature, as they control for the selection bias resulting from the possibility that countries may not choose their ERR independently of their trade flows.

\section{Conclusion}

An essential question facing a trade policymaker is which exchange rate regime to adopt. Previous literature has reported a significant positive effect of adopting a fixed exchange rate regime on the bilateral trade between a pegging country and its base country. This paper argues that results from a typical ordinary least squares regression using the augmented gravity model of international trade should not be interpreted as causal effects because of the endogeneity problem. To address the causal nature of this question more precisely, this paper uses different propensity score matching methods proposed in the treatment evaluation literature to compare treated (fixed ERR) and control (flexible ERR) countries.

Using different propensity score matching methods, and data covering 196 countries comprising almost 100 percent of the world's trade during the 1973 2006 period, it appears that fixed ERRs do indeed lead to more bilateral trade between the pegging country and its base country. This effect, on the order of 25-50 percent, is statistically significant and can be safely interpreted as a causal effect. This suggests that there is little bias in conventional OLS estimates, which are fairly close to the range reported in this paper using different propensity score matching techniques.

Received 19 March 2013, Revised 22 April 2013, Accepted 11 June 2013 


\section{References}

Abadie, A., D. Drukker, J. Herr, and G. Imbens. 2004. Implementing matching estimators for average treatment effects in Stata. The STATA Journal 4 (3): pp. 290-311.

Abadie, A. and G. Imbens. 2002. Simple and bias-corrected matching estimators. Technical Report, Department of Economics, University of California, Berkley.

Adam, C. and D. Cobham. 2007. Exchange rate regimes and trade. The Manchester School 75 (Supplement1): pp. 44-63.

Baranga, T. 2010. Estimating the effects of fixed exchange rate regimes on trade: Evidence from the formation of the Euro. Working Paper.

Becker, S. and A. Ichino. 2002. Estimation of average treatment effects based on propensity scores. The STATA Journal 2 (4): pp. 358-377.

Bergin, P. and Ching-Yi Lin. 2008. Exchange rate regimes and the extensive margin of trade. NBER Working Paper no. 14126. National Bureau of Economic Research, Cambridge: MA.

Caliendo, M. and S. Kopeinig. 2008. Some practical guidance for the implementation of propensity score matching. Journal of Economic Surveys 22 (1): pp. 31-72.

Cochran, W. 1968. The effectiveness of adjustment by subclassification in removing bias in observational studies. Biometrics 24 (2): pp. 295-314.

Feenstra, Robert C., James R. Markusen, and Andrew K. Rose. 2001. Using the gravity equation to differentiate among alternative theories of trade. Canadian Journal of Economics 34 (2): pp. 430-47.

Glick, R. and A. Rose. 2002. Does a currency union affect trade? The time series evidence. European Economic Review 46 (2002): pp. 1125-1151.

Heckman, J. and R. Robb. 1985. Alternative models for evaluating the impact of interventions. In J. Heckman and B. Singer (eds), Longitudinal Analysis of Labor Market Data (pp. 156-245). Cambridge: Cambridge University Press.

Heckman, J., H. Ichimura and P. Todd. 1997. Matching as an econometric evaluation estimator: Evidence from evaluating a job market programme. Review of Economic Studies 64 (4): pp. 605-654.

Heckman, J., H. Ichimura and P. Todd. 1998. Matching as an econometric evaluation estimator. Review of Economic Studies 65: pp. 261-294.

Holland, P. W. 1986. Statistics and causal inference. Journal of the American Statistical Association 81: pp. 945-970.

Klein, M. and J. Shambaugh. 2006. Fixed exchange rates and trade. Journal of International Economics 70 (2006): pp. 359-383.

Lechner, M. 1999. Earnings and employment effects of continuous off-the-job training in East Germany after unification. Journal of Business \& Economic Statistics 17 (1): pp.74-90.

Morgan, S. and D. Harding. 2006. Matching estimators of causal effects: Prospects and pitfalls in theory and practice. Sociological Methods \& Research 35 (1): pp. 3-60.

Nichols, A. 2007. Causal inference with observational data. The STATA Journal 7 (4): pp. 507-541. 
Rose, A. 2000. One money, one market: The effect of common currencies on trade. Economic Policy 15 (30): pp. 9-45.

Rose, A. 2001. Currency unions and trade: The effect is large. Economic Policy 16 (33): pp. 449-461.

Rose, A. 2004. Do we really know that the WTO increases trade? The American Economic Review 94 (1): pp. 98-114.

Rose, A. and M. Spiegel. 2011. The Olypic effect. The Economic Journal 121 (553): pp. 652-677.

Rosenbaum, P. and D. Rubin. 1983. The central role of the propensity score in observational studies for causal effects. Biometrika 70 (1): pp.41-50.

Rubin, D. 1973a. Matching to remove bias in observational studies. Biometrics 29 (1): pp. 159-183.

Rubin, D. 1973b. The use of matching sampling and regression adjustment to remove bias in observational studies. Biometrics 29 (1): pp. 185-203.

Shambaugh, J. 2004. The effect of fixed exchange rates on monetary policy. The Quarterly Journal of Economics 119 (1): pp. 301-352.

Smith, J. and P. Todd. 2005. Does matching overcome LaLonde's critique of nonexperimental estimators? Journal of Econometrics 125: pp. 305-353. 